Key words: Mental health care, Financing, Costs, services, Mental health policy, Spain

\title{
Financing Mental Health Care in Spain: Context and critical issues
}

\author{
L. Salvador-Carulla* \\ M. Garrido** \\ D. McDaid ${ }^{\star \star *}$ \\ J.M. Haro
}

* President. PSICOST Research

Association, Jerez, Spain

** Technical Advisor. Department of Mental Health and Substance Abuse. WHO, Geneva

${ }^{* * \star}$ Research Fellow, LSE Health and Social Care and European Observatory on Health Systems and Policies, London School of Economics, London, England

${ }^{\star * * \star}$ Fundacio Sant Joan de Deu. Barcelona, Spain. Chair RIRAG Research Network

SPAIN

\footnotetext{
ABSTRACT - Background: Financing and the way in which funds are then allocated are key issues in health policy. They can act as an incentive or barrier to system reform , can prioritise certain types or sectors of care and have long term consequences for the planning and delivery of services. The way in which these issues can impact on the funding of mental health services across Europe has been a key task of the Mental Health Economics European Network. (MHEEN) This paper draws on information prepared for MHEEN and provides an analysis of the context and the main issues related to mental health financing in Spain.

Methods: A structured questionnaire developed by the MHEEN group was used to assess the pattern of financing, eligibility and coverage for mental healthcare. In Spain contacts were made with the Mental Health agencies of the 17 Autonomous Communities (ACs), and available mental health plans and annual reports were reviewed. A direct collaboration was set up with four ACs (Madrid, Navarre, Andalusia, Catalonia).

Results: In Spain, like many other European countries mental healthcare is an integral part of the general healthcare with universal coverage funded by taxation. Total health expenditure accounted for $7.7 \%$ of GDP in 2003 (public health expenditure was $5.6 \%$ of GDP). Although the actual percentage expended in mental care is not known and estimates are unreliable, approximately $5 \%$ of total health expenditure can be attributed to mental health. Moreover what is often overlooked is that many services have been shifted from the health to the social care sector as part of the reform process. Social care is discretionary, and provides only limited coverage. This level of expenditure also appears low by European standards, accounting for just $0.6 \%$ of GDP.
} 
Comments: In spite of its policy implications, little is known about mental healthcare financing in Spain. Comparisons of expenditure for mental health across the ACs are problematic, making it difficult to assess inequalities in access to services across the country. The limited data available on mental healthcare expenditure suggests that level of funding for mental health is low compared with many of the EU-15 countries. This may indicate inefficient and inequitable funding given the significant contribution of mental disorders to the overall burden of ill health. Attention needs to be directed to redressing both the information deficit and also in using a range of financing mechanisms to promote greater investment in mental health.

\section{Introduction}

In recent years, growing attention has been paid to the economics of mental disorders which account for $20 \%$ of all disabilityadjusted life years, and $43 \%$ of all years lived with a disability in the WHO European Region (WHO 2001). However, despite the significant health, economic and social costs of mental health problems, and the increasing body of evidence on effective interventions, the development of mental health policy and practice seems neglected in Europe, in comparison with other health sectors.

Financing is a key issue in health policy. It sets up incentives or barriers, can prioritise care in one sector over another and has long term consequences on how care is provided and organised. While much is known on the ways in which general health care systems are financed in Europe, little has been published specifically on the financing of mental health (Knapp et al. 2003). Looking at mental health is also important given the degree to which services are provided outside the health care sector in different countries, with implications both for the level of fairness in access to services and also in moving towards a greater degree of harmonisation in the delivery of mental health care services across Europe. An important first step therefore is to collect and analyse information on how mental health services are provided and financed across the European Union. This paper is intended to provide such an overview for Spain.

\section{Methods}

The Mental Health Economics Europe Network (MHEEN) was established in 2002 with support from the European Commission in order to look at some of the key issues related to mental health policy and economics initially across the original 15 EU Member States, Iceland and Norway. MHEEN is a partnership of health economists, policy analysts and mental health professionals working in collaboration with Mental Health Europe, a non-governmental organisation (McDaid et al. 2005a). A key element of the work undertaken by MHEEN is to map current structures and service provision in Europe in order to provide a baseline and context for comparative analysis and development of policy recommendations. In order to assess mental health financing systems across EU countries, a structured questionnaire was developed iteratively by the group to examine, firstly, the extent to which mental health services may be funded in a different fashion to other health care services, and to consider whether the approaches are efficient and equitable. A second purpose was to review the extent to 
which services are provided outside the health care sector, for instance by social services and the consequences for entitlement and access to services. Gaps in the availability of information were also identified by the group (for detailed description see http:// www.mentalhealth-econ.org/).

In Spain, data collection and reports were carried out by two researchers (LS and MG) from the PSICOST/RIRAG research thematic network. As the responsibility for health care in Spain is devolved to 17 Autonomous Communities, contacts were made with their mental health agencies, and available mental health plans, annual reports and technical documents were reviewed. A direct collaboration was set up with four ACs (Madrid, Navarra, Andalucia, Cataluña) which account for $50 \%$ of the total population of Spain. The mental health care system including financing was thoroughly reviewed in these ACs for the reference year 2002 .

This paper provides a synthesis and analysis of the Spanish report prepared by the Psicost/RIRAG group (Red de Investigacion de Resultados Aplicados a la Gestión) \& the Spanish Society of Psychiatric Epidemiology (SEEP) for the MHEEN project. The paper begins by outlining the history and the financing pattern of the general healthcare system in Spain including the role played by user charges and private health insurance. The next section then considers the background to and financing of mental health care. Section 3 reviews eligibility for and coverage of both general and then mental healthcare services, Section 4 turns to entitlements to mental health services in other sectors, in particular within social care and provides an overview of financing mechanisms for these services.

\section{Results}

\section{The structure and financing of health care in Spain}

\section{The Spanish healthcare system}

During the last 25 years, three parallel processes have had a major impact on the organisation and financing of mental health care: devolution of responsibility for health from national to regional agencies, as well as both health system and mental health reform. The combination of these dynamic processes has produced an extremely complex situation, which makes the description of the current organisational and financial structure of the system a difficult task.

The system can be characterised as an integrated National Health Service, publicly financed that provides almost universal health care free of charge at the point of use. Provision is mostly publicly owned and managed: this applies to most general practitioners and primary health care centres, to outpatient specialised clinics and physicians, and to $80 \%$ of hospital care.

Governance of the health care system is now fully decentralised with responsibility resting with each of the 17 "Autonomous Communities" (ACs) or regions that make up the Country. The health care system in the "autonomous cities" of Ceuta and Melilla located in north Africa is the responsibility of the national Ministry of Health. Each AC e.g. Catalonia, Extremadura or Asturias has their own government and administration, and in addition to full responsibility for health and social services, they also have varying degrees of autonomy for other issues such as crime and justice or education.

The process of decentralisation in Spain has developed at a different pace in every AC 
depending on regional policy and the model used for administrative transfer from central government. Two different AC transfer models were developed in the late 1970's: a "slow" transfer process and a "quick" one for the so-called "Historical" ACs. Responsibility for health care was transferred to Catalonia from 1981, followed by Andalucia in 1984, the Basque Country and Valencia in 1987, Galicia and Navarra in 1990 and the Canary Islands in 1994. However it was not until 2002 that the devolution process to all the ACs was completed.

Decentralisation has led to a greater diversity in the organisation of health and social care services. For example, while Catalonia and Andalucia both secured control over health services in the 1980s, in Catalonia responsibility for social care services were also devolved at the same time, whereas in Andalucia this did not happen until the 1990s. In contrast in another 10 ACs, devolution of responsibility for social care preceeded that for health care, e.g.in Cantabria and Balearic Islands this happened in 1997, while the transfer of responsibility for health care services from the national health agency (INSALUD) was only completed in 2002 (Lopez-Casasnovas 2002, Cantarero-Prieto 2002).

Another challenge in the evolution of the health care system across the country is that the process of decentralisation has not been accompanied with a parallel development of national agencies or efficient cross-regional coordination systems. Decisions as to what services to make available are now determined regionally, subject to some loose coordination and agreement with the Council of the National Health System. Currently there is no national information system on service provision, planning or financing either for social or health services. This situation has been defined as being "specially chaotic in terms of territorial power sharing" (European Observatory on Health Care Systems 2000a). The Spanish health observatory released its first national report in 2004 (Observatorio Nacional de Salud 2004), but it provides little information on the mental health system. Major differences have emerged among ACs in other areas such as law, education and criminal justice.

\section{Health care financing}

The Spanish National Health System was set up in 1986 when the General Health Care Act was approved by the Spanish Parliament. This introduced a system funded through general taxation with funds pooled at a national level. (Navarra and the Basque country are exceptions see below) This replaced the previous social insurance based system which had collected contributions from employers and employees through one general sickness fund and a small number of specialist group funds intended to increase pension and health care coverage. (To this day this social security general fund continues to provide pension coverage) A new financing model was set up by the National Council of Tax and Financing Policies (Consejo Nacional de Política Fiscal y Financiera $-C P F F$ ) following the enactment in December 2001 of a law completing the integration of health financing within the general financing system. (Cantarero-Prieto 2002, SánchezMaldonado \& Cabases, in press).

Health care expenditure accounted for approximately $7.7 \%$ of its GDP in 2003 while total health expenditure per capita was 1,835 US \$ (PPP: Purchase Power Parity) (OECD Report 2005). In comparison, UK total health expenditure per capita was 2,231 US \$ PPP for the same period. 71.2\% of total health care expenditure is publicly funded, of which taxation accounts for $98 \%$, while private expenditure through user 
charges is approximately $24 \%$ and private health insurance just $4 \%$ of total health care expenditure. The percentage of public health expenditure has been relatively stable over the last decade ranging from between $5.3 \%$ and $5.8 \%$ of GDP, in part attributed to a wage constraint policy and low investment (Sanchez-Maldonado \& Cabasés, 2005). Mean public health expenditure per person was 1,053.46 euros in 2005 (range between 973 and 1237 euros), while it was 995 in 2003. The overall public health expenditure for 2005 was over 45 billion euro. One notable feature of the system is the high rate of drug expenditure as a percentage of the total health expenditure $(21.8 \%$ in year 2003) (Ministerio de Sanidad y Consumo 2003, OECD 2005).

All ACs except for Navarra and the Basque Country, are under a common taxation system called regimen común. The allocation of funds from general taxation to the various ACs is laid out in the State Budget Act of the Spanish Parliament every year. The Canary Islands have a special taxation system as an overseas region within the European Union. Funds for all services (including health care) are collected from regional shares of income $\operatorname{tax}(33 \%)$, VAT $(35 \%)$, excise duties $(40 \%)$ and $100 \%$ of other taxes (e.g. car registration and property tax, beverages and oil taxes). A detailed breakdown is described elsewhere (Cantarero-Prieto 2002, Cabases \& Utrilla 2005). Part of VAT is directly given to the ACs, except for the Basque Country and Navarra, which are under a special taxation system called Regimen Foral. These two ACs directly collect taxation and transfer a fixed quota to central government on the basis of annual negotiations (сирo). Therefore these ACs have full governance of both the financing and organisation of the health and the social care system. Other ACs have been pressing for similar agreements, however this process was halted in 2004, when the negotiation of a new general statutory agreement between each Autonomous Community and the Central Government commenced Estatutos de Autonomía. This new estatutos include changes in the healthcare funding system that vary from one AC to another. The new Estatuto of the Comunidad Autónoma de Valencia was finished in June 2005, and the Estatuto of Catalonia started revision by the Spanish Parliament in November 2005 (a similar arrangement to the Basque Country with an specific approach to healthcare financing has been requested).

Overall the ACs are responsible for managing over $90 \%$ of public health expenditure (92\% in 2006). A model for inter-territorial equity was developed when the devolution process finished. However an increasing number of compensation funds to ACs have been approved to favour inter-territorial equity and to attenuate the increasing health deficit. The complexity of this system is illustrated through the additional health budget share provided by the central government to the ACs in 2006 (Table I). $44.87 \%$ (1,365.4 million euro) are advanced payments from taxes and from the Sufficiency Fund Fondo de Suficiencia. The sufficiency fund is a central transfer equalisation which is made to every AC by the Spanish government to maintain social solidarity between the different ACs. This fund is divided into three components: national or central services, health services and social services. For the last two components, the level of transfer is based on a index adjusted by the number of users of public services in every AC. Two adjustment are made according to the age structure of the population and to the geographical location in Canary or Balearic Islands. The model determines the minimum budget to be allocated to health and social services 
by the ACs Principio de Afectación, and the minimum transfer to be provided by central government to every AC. The other 53.13\% (1,677 million euro) are specific health funds. They include: 1) Health warrant fund Fondo de Garantía Sanitaria (500 million euro). This fund warrants additional funds if tax revenues are declining in any one $\mathrm{AC}$ or their increase is below the Spanish GNP (the sufficiency fund restrains health overexpenditure in relation to GNP, but needs to compensate regional GNP declines); 2) Direct transfer to ACs (500 million euro); 3) Patient mobility fund Fondo de Cohesión Sanitaria (50 million euro). This compensation fund ensures that there is a transfer of funds across the ACs to reimburse the hospital expenses of patients resident in a different AC; and care provided to foreign citizens (see healthcare eligibility below); 4) Compensation fund to Islands (Canary and Balearic Islands) (55 million euros); 5) A quality and equity program (Plan de Calidad e Igualdad del Sistema Nacional de
Salud) (55 million euro). This plan provides additional compensation funds for equity in health care across the different ACs; 6) Care to foreigners (200 million euro). This fund compensate to ACs for care provided to foreign citizens and not reimbursed from the Countries of origin. 7) Fund for care due to uninsured accidents (100 million euro); and 8) Compensation fund for the health deficit (227 million euro). A new tax on beverages and tobacco was introduced in 2005 for partial compensation of the health deficit in the ACs. Apart from these funds, the law entitles ACs to collect special health taxes on gasoline, electricity, and car registrations (these taxes are optional for every one AC). A total health revenue of 1.800 million euro is expected from these regional taxes in 2006.

The financial deficit reached 4.3 billion euros in the first quarter of 2005 (Grupo de Trabajo de Análisis del Gasto Sanitario Público 2005) and it is estimated to climb to 5 billion euro in 2006 .

Table I

Transfer to ACs from the Ministry of Health estimated for fiscal year 2006 in Spain (apart from the health budget directly managed by ACs) (Ministerio de Sanidad y Consumo, 2005).

Sources of funding

Million euro

Advance payments and sufficiency funds (based on census 2004)

$1,365.4$

Special Health funds from the central government

- Direct transfers to Acs

- Quality \& Equity program (1)

- Compensation Patient mobility fund (2)

- Compensation Funds for Islands

- Health warrant fund (3)

- Care for foreigners

- Care due to uninsured accidents

- Special taxation on Alcohol \& Tobacco

Total public health budget transfer from the Ministry of Health to ACs (2006)

(1) "Plan de Calidad e Igualdad del Sistema Nacional de Salud".

(2) "Fondo de Cohesión Sanitaria".

(3) "Fondo de Garantía de Financiación Sanitaria". 
The factors related to the health deficit are complex and include circumstances specific to Spain such as the lack of coordination among ACs , the "expenditure culture" which characterised health management in some ACs, and the $8 \%$ population increase in the last 5 years mainly due to immigration (the sufficiency fund used the 1999 census until 2005 despite the additional 3.7 million new citizens). The non-reimbursed care to foreign citizens is mounting although there is no estimate available. An on-going EU project (Europe for Patients), has found that most reimbursement forms for EU citizens are not completed at the hospitals, and many ageing EU citizens who actually live in Spain do not transfer their pension rights although they receive long term care. The provisional measures to redress the deficit are insufficient. A new model for financing is due to be established in 2007 (Cantarero-Prieto 2002, Sanchez-Maldonado \& Cabasés 2005). New financing schemes are being piloted in some areas. For example, a capitation scheme including both health, long-term care and social care is being tested in several counties in Catalonia.

\section{User charges}

In addition to funds raised through taxation, user charges continue to play a significant role. Survey data indicate that the payment of user charges to both the public and the private systems amounted to approximately $17 \%$ of total health care expenditure. It accounts for over 70 to $85 \%$ of total private expenditure (which accounts for $33 \%$ of the total health expenditure in Spain) (Casado y López-Casasnovas 2001). There is cost-sharing for pharmaceuticals; the general population pays $40 \%$, the disabled $10 \%$ but the elderly are exempt. Although children and unemployed are not exempt, it has been estimated that the actual global copayment is $7 \%$ of medication expenditure.
Of these payments, $57 \%$ were direct payments for private out-patient care (including nursing care), $3 \%$ were direct payments for in-patient care; and $40 \%$ were co-payments for pharmaceuticals, and orthopaedic prosthetic products (European Observatory on Health Care Systems 2000b).

\section{Private health insurance}

Private health insurance plays a secondary, albeit increasing, role in Spain. Several comparisons with other EU countries have been published which indicate that the proportion of the population with private health insurance increased from $8.9 \%$ in 1997 (Ruiz 2002) to $12.6 \%$ in 2000 (UNESPA, Carles and Oliva 2002), and $13 \%$ in 2002 (OECD 2005). Moreover a 2004 national survey found that publicly funded health use decreased from $90 \%$ in 1994 to $83 \%$ in 2004 (Instituto de Estudios Fiscales 2004). Of the 5 million plus consumers of private health insurance in 2000 (UNESPA), over 2 million were members of the national mutual fund for civil servants (MUFACE); with the remainder having other commercial insurance schemes.

This increase in the use of private insurance is in part due to health reforms that have encouraged the expansion of this sector, especially in respect of the management of occupational health and accidents at the workplace. Tax deductions are also provided for employer purchased private insurance. Health insurance companies also run care delivery organisations. Public contract of care services with private companies have had a positive on private health insurance. Within Spain, Catalonia has had a long standing tradition of not for profit health insurance, but this has to a great extent been replaced by for-profit private insurance in the last decade, which now accounts for most contracts within this sector. 
According to 2002 estimates, private insurance is the primary method of funding health care for $2.7 \%$ of the population while for the other $10.3 \%$ of population with private insurance, this acts as a complement or supplement to their use of the public system. Typically this allows for faster access to services and is argued to increase consumer choice. Exceptionally it can provides complementary coverage for services excluded by the NHS, such as dentistry.

Half of all civil servants entitled to participate in the national mutual fund choose to be treated through private insurance. However there is some evidence suggesting that this group of people use public sector providers for high technology interventions, and also switch to the public health care system care when expensive treatment for chronic conditions is required.

Perhaps unsurprisingly given both the high level of civil servants with private insurance and also because of reforms in Catalonia that have encouraged the purchase of private health insurance, between $20 \%$ and $25 \%$ of all those with private health insurance are located in Madrid and Barcelona. The profile of those with private insurance differs from general population (they are married, with children, age between 25-45, with an academic degree and a stable job).

\section{The structure and financing of the mental health care system}

In Spain, psychiatric care is one of the most neglected areas within the health system due to the longstanding fragmentation of responsibility for services among various public administration bodies, coupled with a lack of coordination, reliance on religious charitable organisations, chronic underfinancing and a lack of interest in the field by most central and regional authorities. Like many other countries in Europe much reform has focused on reducing the reliance on long stay psychiatric institutions. Reforms of the system started in earnest in 1985 with the release of the report of the two year Ministerial Commission for Psychiatric Reform. The report has led to different structural consequences across the ACs. For example, Andalucia closed all of its psychiatric hospitals by 2001 while Catalonia continues to retain residential subacute (time-limited) and long term care within psychiatric institutions. These reforms have been described at length in a series of national and international reports and papers (see Vázquez-Barquero \& Garcia 1999, Salvador-Carulla et al. 2002 for a review).

The General Health Act (1986) made provision for the integration of mental health within the general health care system and stated that psychiatric patients should be considered as service users of equal worth. Subsequently, mental health networks were integrated in the general health system. Psychiatric care, except for psychoanalysis and hypnosis, was included among the package of benefits covered by the National Health System (Real Decreto 63/1995) and specific Diagnostic-Related Groups (DRGs) tariffs for mental disorders were added to the national DRG system. As in other European countries, DRG tariffs can be largely inaccurate tending to underestimate costs and moreover are outdated having not been revised in recent years.

In common with the situation found other European countries with NHS style systems, mental health care is integrated within the public health system and therefore largely reliant on public funding. Thus the financing mechanisms are no different to those for other health care sectors, as services receive most of their funding from a 
share of taxation revenues. Each AC chooses how to allocate the health budget to meet health needs, thus there may be variation in the levels of funding received in different ACs, although this is difficult to determine because of deficits in our knowledge of mental health expenditure in the country (See next section). However in common with the situation found in many European countries, health reform have included the transfer of some services for people with mental disorders and for those with intellectual disabilities out of the health sector and usually to the social care sector. Such service transfers include non-hospital residential care, occupational care and other intermediate care facilities. Psychiatric care for special populations such as those with intellectual disabilities, drug addiction or in need of psychogeriatric care e.g. for dementia have also been transferred to social services in many ACs. As we indicate later on one consequence of such transfers can be reduced access and entitlement to services.

Unfortunately, there is no estimate of the proportion of total health care expenditure allocated to mental health services. At a national level Spain was unable to provide an estimate for the recently updated WHO Mental Health Atlas (2005). A recent estimate suggest that mental health should account for $5 \%$ of total health expenditure, being the third lowest in EU-25 (MHEEN 2004). However, this estimate is very crude and not based on robust data. We attempted to carry out a detailed analysis of mental health expenditure in four ACs (Andalucia, Catalonia, Madrid and Navarre) for year 2002 (Salvador-Carulla et al. in press). The results were not encouraging and illustrate the challenge in estimating mental health expenditure. In the Community of Madrid no information was available while in Andalucia the method of compiling available data meant that it was impossible to disaggregate mental health from other hospital or outpatient expenditures. Where some information was available (Catalonia and Navarre), the accounting procedures used differ making comparison between the two ACs impossible. Notwithstanding these caveats above Table II provides some estimate of mental health expenditure in three of these ACs (Catalonia, Navarre and Andalucia).

\section{Table II}

Health expenditure and mental health share in 3 Autonomous Communities (AC) in Spain: Catalonia, Andalucia, and Navarre (reference year: 2002).

\begin{tabular}{lccc} 
& Catalonia & Andalucia & Navarre \\
\hline Total Annual Health Exp. & 4,437 mill. $€$ & 5,703 mill. $€$ & 499 mill.€ \\
Annual Mental Health Exp. & 239 mill. & N. A. & 23 mill. $€$ \\
Annual per capita Health Exp. & $700 €$ & $775.12 €$ & $897.76 €$ \\
Annual Exp. applied to Mental Health & $5.39 \%$ & N. A. & $4.61 \%$ \\
$\quad$ \% of total Health Exp.) & $37.69 €$ & N. A. & $41.38 €$ \\
Annual per capita M.H. Exp. & 1,142 mill. $€$ & 1,192 mill. $€$ & 88 mill. $€$ \\
Annual Drug Exp. & 118 mill. $€$ & 88 mill. $€$ & 10 mill. $€$ \\
Annual Exp. in Psychotropic Drugs & $18.60 €$ & $11.96 €$ & $17.99 €$ \\
Annual per capita Exp. in Psychotropic Drugs & 10.33 & 7.38 & 11.36 \\
\% Psychotropic Exp. in relation to total Drug Exp. & 10.36
\end{tabular}

N. A.: Information not available at the time of completion / Exp: Expenditure / MH: Mental Health. Information provided and checked with regional health authorities. The indicators for mental health expenditure vary from one AC to other, so they are not fully comparable. Psychotropic drugs include antipsychotics and antidepressants. 
Looking beyond funding from taxation and user charges, there appears to be a limited role for private insurance coverage for mental health while there continues to be some reliance on the role of charitable organisations including the church in providing residential service provision, towards whose costs residents may typically make a contribution. This situation explain why there may be a lower proportion of publicly financed mental health care expenditure in comparison to general health $(76 \%)$, with lower private insurance expenditure, and higher out-of-pocket expenses.
A summary of mental health care statistics from the WHO Atlas and four ACs in Spain for year 2002 in Table III also suggests that resources for mental health are limited. The Atlas indicates that the number of psychiatrists working in the public sector in Spain is half the average in European countries, with similar observations found for other human resources. (WHO 2005, Salvador-Carulla et $a l$. in press). In spite of similar psychiatric systems, the rate of mental health resources is lower in Spain than in Italy (Salvador-Carulla et al. 2005) It is also clear that cross national comparisons alone only tell part of the story,

Table III

Mental Health Care Indicators in Europe, Spain and four Autonomous Communities Rate (and total numbers) of psychiatric beds per 10,000 inhabs, and rate (and total numbers) of mental health professionals per 100,000 inhab.

\begin{tabular}{|c|c|c|c|c|c|c|}
\hline & Europe & Spain & Catalonia & Andalucia & Madrid & Navarre \\
\hline Total Psych Beds & 8.70 & 4.4 & $\begin{array}{c}8.30 \\
(5,263)\end{array}$ & $\begin{array}{c}2.35 \\
(1,732)\end{array}$ & $\begin{array}{c}2.95 \\
(1,600)\end{array}$ & $\begin{array}{l}5.13 \\
(285)\end{array}$ \\
\hline Psych Beds in Psych Hospitals & N. A. & 3.7 & $\begin{array}{c}6.57 \\
(4,165)\end{array}$ & $\begin{array}{l}0.04 \\
(32)\end{array}$ & $\begin{array}{c}1.94 \\
(1,050)\end{array}$ & $\begin{array}{l}0.92 \\
(51)\end{array}$ \\
\hline Psych Beds in General Hospitals & N. A. & 0.6 & $\begin{array}{c}0.76 \\
(480)\end{array}$ & $\begin{array}{c}0.75 \\
(554)\end{array}$ & $\begin{array}{c}0.58 \\
(313)\end{array}$ & $\begin{array}{l}0.97 \\
(54)\end{array}$ \\
\hline Psychiatrists & 9.00 & 3.6 & $\begin{array}{c}7.06 \\
(447.99)\end{array}$ & $\begin{array}{c}5.29 \\
(389)\end{array}$ & N. A. & $\begin{array}{c}6.71 \\
(37.30)\end{array}$ \\
\hline Psychologists & 3.00 & 1.9 & $\begin{array}{c}4.90 \\
(310.79)\end{array}$ & $\begin{array}{c}2.51 \\
(185)\end{array}$ & N. A. & $\begin{array}{c}4.95 \\
(27.50)\end{array}$ \\
\hline Nurses & 27.50 & 4.2 & $\begin{array}{c}5.75 \\
(364.87)\end{array}$ & $\begin{array}{c}6.02 \\
(443)\end{array}$ & N. A. & $\begin{array}{c}10.08 \\
(56)\end{array}$ \\
\hline Social Workers & 2.35 & N. A. & $\begin{array}{c}2.10 \\
(133.11)\end{array}$ & $\begin{array}{c}1.48 \\
(109)\end{array}$ & N. A. & $\begin{array}{l}3.42 \\
(19)\end{array}$ \\
\hline Psychiatrists in MH Centers & N. A. & N. A. & $\begin{array}{c}3.57 \\
(226.75)\end{array}$ & $\begin{array}{l}2.81 \\
(207)\end{array}$ & $\begin{array}{c}3.50 \\
(190)\end{array}$ & $\begin{array}{c}4.19 \\
(23.30)\end{array}$ \\
\hline Psychologists in MH Centers & N. A. & N. A. & $\begin{array}{c}3.14 \\
(199.05)\end{array}$ & $\begin{array}{c}2.35 \\
(173)\end{array}$ & $\begin{array}{c}2.18 \\
(118)\end{array}$ & $\begin{array}{l}2.52 \\
(14)\end{array}$ \\
\hline Nurses in MH Centers & N. A. & N. A. & $\begin{array}{c}0.91 \\
(57.56)\end{array}$ & $\begin{array}{l}1.33 \\
(98)\end{array}$ & $\begin{array}{l}1.66 \\
(90)\end{array}$ & $\begin{array}{l}2.52 \\
(14)\end{array}$ \\
\hline Social Workers in MH Centers & N. A. & N.A. & $\begin{array}{c}1.08 \\
(68.39)\end{array}$ & $\begin{array}{l}0.99 \\
(73)\end{array}$ & $\begin{array}{l}1.05 \\
(57)\end{array}$ & $\begin{array}{l}1.62 \\
(9)\end{array}$ \\
\hline
\end{tabular}

* Psych: Psychiatric / MH: Mental Health / N. A.: Data not available at the time of completion. Data for Spain and Europe from WHO Atlas on Mental Health (data for Spain refers to year 1996) (WHO 2005). Autonomous Communities data refer to year 2002. In Navarre and Catalonia units refer to 1 full working staff per month. Data from Catalonia are estimates from analysis in 6 small health areas randomly selected. Data for Catalonia and Madrid have been provided by regional services with different counting method. Staff in Mental Health Centers does not count staff in centers for child and adolescent psychiatry in Catalonia and Andalucia. 
as we can see in Table II there is some variation in access to human resources across different ACs. Levels of resources in Andalucia, Catalonia and Navarra in our analysis are in some cases much higher than the national average for Spain published at WHO Atlas (WHO 2005).

\section{Healthcare elegibility and coverage}

\section{General healthcare}

The level of health care coverage is nearly universal in Spain. It is not based on citizenship and following the introduction of the NHS in 1986 eligibility was increased beyond those in employment to cover most of the population. By 1997, it was estimated that $99.4 \%$ of the population was covered by the statutory system (National Health Survey 1997). $94.8 \%$ of the Spanish population were covered under their obligatory affiliation to the social security system or qualified for access through a special non-contributory scheme reserved for those very poor and vulnerable individuals. The vulnerable and disadvantaged are still subject to separate administrative regulations. The remaining $4.6 \%$ of the population $(2,000.000$ people) are covered through three non-profit mutual funds: Social Institute for the Armed Forces (ISFAS), the General Legal Mutual Company (MUGEJU) and the Mutual Fund for State Civil Servants (MUFACE). Approximately $50 \%$ of the members of these mutual funds choose care within the National Health System and 50\% choose coverage through private insurance. $70 \%$ of these schemes are funded by the state with the remaining $30 \%$ coming from enrolee contributions.

Self-employed have a specific scheme within the Social Security which has been given access to the NHS according to professional background, affiliation to professional colleges and other factors. According to the 1997 National Health Survey, the proportion of non-eligible population was $0.6 \%$, largely consisting of high income self employed professionals and employers.

Since 2004 EU citizens can obtain full care access through the European Health Insurance Card. They can also transfer their pension rights to Spain and obtain longterm care. Other legal non-Spanish residents have right of access when employed or when they entitle to the non-contributory scheme. In January 2000 the national Parliament approved the Immigration Act, which entitles registered immigrants to health care benefits on a means-tested basis. It also ratified the right to health care that had already been recognised for immigrant children under 18, immigrant women during pregnancy, as well for all in the case of accidents or emergencies. At present undocumented immigrants have also access to the health care system as they can register in the municipality census and then obtain a regional health card. The homeless and unemployed are included through the special non-contributory scheme, although the degree of coverage for the homeless and seriously disadvantaged is not clear. In most ACs they have to pay the full price of medicines. For example, local councils pay their medicines in the Basque Country.

\section{Mental Healthcare coverage and eligibility}

Coverage and eligibility for mental health care services is exactly the same as that for other parts of the health care system, and individuals are entitled to access to free at the point of use services. The 1986 General Health Act also entitles any individual with a disability, both physical or mental, to access rehabilitation services. In practice 
however, enforcement of this legal entitlement has not been sufficiently developed and thus care and treatment gaps appear in several areas including mental health. Certain categories of treatment are also explicitly excluded from coverage within the NHS, these include psychoanalysis and other dynamic therapies.

\section{Private insurance coverage and mental heath}

Private insurance is risk rated and provides limited coverage for mental disorders; many healthcare plans exclude psychotherapy or psychiatric hospitalisation. However, the reduced availability of service provision and accessibility in the public sector increases the registration of patients seeking substitutory mental health care in private insurance schemes. Data from private insurance companies are not readily available. Furthermore, many patients do not provide previous history of mental illness when registering to a private insurance scheme. Therefore it is difficult to estimate the size of the shift from public to private mental health care in Spain.

\section{Social services for people with disability/dependence}

As we have shown health care is a right in Spain, with near universal coverage for the whole population. Earlier however we noted that as reforms of the Spanish mental health system have developed, an increasing number of services have been shifted into the social care sector. Unlike health care, access and entitlement to social care is discretionary. The long term consequences for financing and for care entitlements in those with severe mental illness have not been adequately addressed until very recently. Before the devolution process started, national social services were coordinated, funded and partly managed through an national agency called IMSERSO (Instituto de Migraciones y Servicios Sociales) within the Ministry of Labour. The transfer of social services to the ACs was completed by 1997, with inter-regional coordination dependent on the Sector Conference on Social Affairs. Thus AC social services are responsible for social and community care for a variety of vulnerable populations including those with intellectual disabilities, physical disabilities, mental disorders, drug addiction as well as older people.

Although the devolution process has been completed, IMSERSO retains several national functions. It has been reorganised in order to focus on the dependent, while other issues around disability have been transferred to a new agency (Dirección General de Coordinación de Políticas Sectoriales sobre la Discapacidad). In December 2004, a full review of the problems and financing of social services for people with disabilities/dependency was published (IMSERSO, Libro Blanco de la Dependencia 2004). A Dependency Act and a National Plan on Dependency will be put before the Spanish Parliament by the end of 2005. Dependency Agencies are being set up in the different ACs (for example, Catalonia approved its Dependency Agency in June 2005). The Ministry of Health and the IMSERSO have put together a taskforce to work out a definition and a package of benefits for conditions requiring inputs from both health and social care (ámbito sociosanitario). The relationship between this taskforce and the new model of care for severe mental illness and other disabilities to be outlined in the National Plan on Dependency is still not clear.

In addition to the provision of social welfare benefits such as disability related pen- 
sions, services provided by social care departments may include any facility for mental health except for hospital residential care and outpatient care. However some regional social services also provide hospital care for special population groups such as intellectual disabilities or drug addiction. At present, social services are neither universal nor comprehensive and major differences exist between the 17 ACs. For instance, in Andalucia all the non-hospital health care and most of intermediate care except for day hospitals are provided through contracts with private organisations by a regional institute (FAISEM) with participation of the regional health council and the social council as well as other partners including family associations. In Catalonia most non-hospital residential care and occupational care for chronic mentally-ill people is provided through contracts with the Catalan Health Service.

A 2004 IMSERSO Report differentiates between three models of social care financing in Europe: 1) Universal coverage through taxes, subject to some limited means testing, as for example in The Netherlands and Scandinavian countries, where social expenditure may reach $3 \%$ of GDP (e.g. Denmark); 2) A mixed social security-based system such as that found in Central Europe and France where social expenditure is around 1\% of GDP. Capitation, specific taxes, and specific insurance systems are available in these countries; 3 ) Limited coverage or assistance-based where care is limited to those without resources. This is the model followed in the Mediterranean Countries including Spain, where publicly funded social expenditure is around $0.5 \%$ of GDP. Clearly the level of funding for social services in Spain is well below the average for the EU-15. Again like with health care expenditure there is no esti- mate of social care expenditure specifically for people with mental health disorders in Spain.

Long term care services are funded through both the health and social care sectors. In Spain, long term care accounts for $0.6 \%$ of GDP; and is projected to rise by 2026 to $0.8 \%$ to $1.2 \%$, approaching the level of expenditure in Central Europe (this includes financing both from the health and from the social services) (Casado \& LópezCasasnovas 2001). As a matter of fact, a mixed social-security model has been suggested by the IMSERSO report (2004).

Coverage and elegibility for non-health sector services

Not only is the over all level of funding low but entitlements to social services are less clear as these services are discretionary. Laws in respect of disability and access to services have been passed both nationally and in several ACs. For people with intellectual disabilities entitlement to social services depends on having receipt of a certificate of disability provided by the relevant local authority. The situation for those with other mental health needs is far more complex and varies greatly from one AC to the next. In several ACs, a request must be completed by a psychiatrists and passed on to local social services which then approve coverage. In another AC for instance Andalucia, an inter-sectoral agency provides both authorisation and care.

By contrast the number of staff for special educational needs and support services is far beyond the real level of need. Special educational needs are discussed in legislation (Real Decreto 696/95) and minimum standards have been developed in the ACs. Elsewhere employment has generated a significant amount of standards and laws in Spain. Some are specific to people with dis- 
abilities (for instance the Law for the disabled - LISMI), while others are more general laws or standards that contain provisions relevant to people with disabilities. They include social security disability and pensions legislation, pensiones asistenciales and pensiones no contributivas, as well as fiscal benefits related to disability. Incentives such as discounts and social security bonuses are available if a person registered as disabled is hired by a firm. There is a legal requirement that at least $4 \%$ of the workforce in enterprises with more than 50 employees should be registered disabled. In practice however this regulation is largely overlooked, and in any event it may be the case that people with physical disabilities are favoured over those with mental illness. Unlike social welfare benefits, vocational rehabilitation services are discretionary and constrained by the locally determined budget. In addition there is little investment by private companies in programmes for the detection, treatment and support of mental disorders in contrast to those increasingly seen in a number of European countries and longstanding in the USA. (McDaid et al. 2005b)

\section{Conclusion}

The mechanisms used to collect funds and to allocate them among different areas within the health sector can act as a key barrier or incentive to the further development, co-ordination and quality of health care services. Twenty years after beginning the organisational reform of the Spanish psychiatric system, this is, to our knowledge, the first paper focused on financing of mental health care in Spain. It appears that this area of the health system has been largely ignored by both national and many regional agencies. The imbalance in available information and funding for general healthcare and mental care has been highlighted as a key problem in many countries (Saxena et al. 2003). The ACs now have full responsibility for health care budgets, including the planning and delivery of mental health services, but different accounting mechanisms make it difficult not only to estimate overall levels of expenditure on mental health, but also to ascertain the extent of inequalities in access to and provision of services. This lack of information may be explained by several factors. In Spain mental health policy, planning, and financing was incorporated into the general health system well after this had been developed. This fact compounds the inherent difficulties of the mental health sector, the uneven health devolution process across the ACs, differences in the extent to which services have been shifted into the social care sector and the ongoing transformation of financing arrangements between the ACs and the national government. Other factors to take into account include the lack of a national health and social care information system, and the lack of actual coordination and information sharing across the ACs, and between the $\mathrm{ACs}$ and the central government. These problems may even increase when the new statutory agreements between the central and the regional governments are completed. The new model both of long term care and care for specific dependent populations may not take into account populations with severe mental illness.

The information available on health and social expenditure in mental health in Spain is both scarce and very crude, it is subject to many limitations, and the analysis of the financing system in just four ACs is not representative of the situation in the 17 ACs. 
However, available estimates suggest that there is a low level of expenditure both in health and social services for mental health problems, well below the level found in most other western European countries. This lack of funding is both inefficient -because of the substantial benefits that interventions would bring - and inequitable, given the significant burden of mental health problems, and the disproportionate impact they have on the poor. It can also hamper the ongoing reform of mental health systems across the different ACs, as this often requires the injection of additional resources to aid in the continued rebalancing of the system between institutional and community based services during a period where the Spanish general health system is running up increasing deficits. Systems that have been starved of funding and skilled human resources for decades will be in no shape to support major changes to the delivery setting, organisation or processing of care (McDaid et al. 2005a).

Despite these difficulties there has been significant development in services in many ACs, both by public and private organisations. This trend adds to the urgent need for a transparent and standard system for measuring expenditure on mental health within the context of total health and social expenditure, as well as considering new models of financing introduced for mental health and dependent population both at regional and national level. There are many possibilities. One potential approach to take may be to use a process of formal needs assessment to aid in how resources are allocated to mental health. This may help to address some of the imbalance between funding for mental health and other key health priorities. As well as being mindful of these equity concerns it is important to also improve the efficiency in the way in which scarce resources are used. Greater use of information from economic evaluation can aid in this process. A final area for consideration may be the use of innovative mechanisms to help empower service users to purchase health, social care and other services which best meet their needs. A system whereby service users receive a direct personal budget may be one approach to consider, but this would require careful evaluation.

\section{Acknowledgements}

This review has been produced for the Mental Health Economic European Network (MHEEN) by PSICOST/RIRAG Network in cooperation with the Sociedad Española de Epidemiología Psiquiátrica (SEEP) (Spanish National Society of Psychiatric Epidemiology). MHEEN-I was funded by the Health and Consummer Protection Directorate General, Directorate G - Public Health of the European Commission (SPC.2002397). Psicost/ RIRAG is a Spanish research network, funded by the Instituto de Salud Carlos III (Spanish Ministry of Health) (G03/061). This study has been partly funded by the Catalan Department of Health (CatSalut) and the Spanish Ministry of Health.

\section{References}

Cantarero-Prieto D. Descentralización, transferencias y nueva financiación del sistema sanitario español. In: Cabasés JM, Meneu R, Rodríguez M, San Miguel F, eds. La organización territorial de la sanidad. Pamplona: Universidad Pública de Navarra y Asociación de Economía de la Salud; 2002.

Carles M, Oliva M. Costes de sustitución en el mercado de seguros sanitarios privados en España. In: Cabasés JM, Meneu R, Rodríguez M, San Miguel F eds. La organización territorial de la sanidad. Pamplona: Universidad Pública de Navarra y Asociación de Economía de la Salud; 2002. 
Casado D, López-Casasnovas G. Vejez, dependencia y cuidados de larga duración. Situación actual y perspectivas de futuro. Colección Estudios Sociales $n^{\circ} 6$. Barcelona: Fundación La Caixa; 2001.

European Observatory on Health Care Systems . Health Care Systems in Transition: Spain [on line]. 2000a. (Date of access 1 March 2005). Available from URL: http://www.euro.who.int/document/e70504.pdf.

European Observatory on Health Care Systems . Countryspecific "HiT" Summary: Spain [on line]. 2000b. (Date of access 1 March 2005). Available from URL: http://www. euro.who.int/document/Obs/SPAsum112002.pdf.

Grupo de Trabajo de Análisis del Gasto Sanitario Público. Informe. Intervención General de la Administración del Estado y Conferencia de Presidentes. Madrid: Ministerio de Sanidad y Consumo; 2005.

IMSERSO. Libro Blanco de la Atención a las Personas con Dependencia en España. Madrid: Ministerio de Trabajo y Asuntos Sociales (MTAS), IMSERSO; 2004.

Instituto de Estudios Fiscales. Opiniones y actitudes de los españoles en 2004. Madrid: Ministerio de Hacienda; 2005.

Knapp M, Novick D, Genkeer L, Curran M, McDaid D, SOHO Study Group. Financing health care in Europe. Context for the SOHO Study. Acta Psychiatr Scand 2003; 416(Suppl): s30-s40.

López-Casasnovas G. The devolution of health care to the Spanish regions reaches and end-point In: Cabasés JM, Meneu R, Rodríguez M, San Miguel F eds. La organización territorial de la sanidad. Pamplona: Universidad Pública de Navarra y Asociación de Economía de la Salud; 2002.

McDaid D, Curran C, Knapp M. Promoting mental well-being in the workplace: a European policy perspective. Int Rev Psychiatry. 2005; 17(5): 365-373.

McDaid D, Knapp M, Curran C. Mental Health III. Funding mental health in Europe. European Observatory on Health Systems and Policies. Geneve: World Health Organization; 2005.12.

Ministerio de Sanidad y Consumo. Atlas de la Sanidad en España. Madrid: Instituto de Información Sanitaria. Ministerio de Sanidad y Consumo, 2003.

Observatorio del Sistema Nacional de Salud (SNS). Informe Anual del Sistema Nacional de Salud 2003. Madrid: Agencia de calidad del Sistema Nacional de Salud. Ministerio de Salud y Consumo, 2004. (Date of access 20 November 2005) Available from URL: http://www.msc.es/diseno/sns/sistemanacionalsalud.htm.
Organisation for Economic Co-operation and Development. OECD Health Data 2005. Statistics and Indicators for 30 Countries. Paris: OECD Publishing; 2005.

Ruiz J.El seguro de asistencia sanitaria privada en la Unión Europea”, In: Cabasés JM, Meneu R, Rodríguez M, San Miguel F, eds . La organización territorial de la sanidad. Pamplona: Universidad Pública de Navarra y Asociación de Economía de la Salud; 2002.

Salvador I (Ed.). El Observatorio de salud mental: Análisis de los recursos de salud mental en España. Diciembre 2003. Documentos Técnicos $n^{\circ}$ 5. Madrid: Asociación Española de Neuropsiquiatría (AEN); 2004.

Salvador-Carulla L, Bulbena A, Vázquez-Barquero JL, Muñoz PE, Gómez-Beneyto M, Torres F. La Salud Mental en España: ¿Cenicienta en el País de las Maravillas? In: Cabasés JM, Villalba JR, Aibar C, eds. Informe SESPAS 2002: Invertir para la Salud. Prioridades en Salud pública. Valencia: Generalitat Valenciana y Escuela Valenciana de Estudios para la Salud; 2002.

Salvador-Carulla L, Tibaldi G, Jonson S, Scala E, Romero C, Munizza C. Patterns of mental health service utilisation in Italy and Spain: An investigation using the European Service Mapping Schedule. Soc Psychiatry Psychiatr Epidemiol 2005; 40: 149-159.

Sánchez-Maldonado J, Cabases J. Análisis y valoración del impacto del nuevo modelo de financiación autonómico en el subsistema sanitario. An R Acad Cienc Morales Polit (in press).

Saxena S, Sharan P, Saraceno B. Budget and Financing of Mental Health Services: Baseline Information on 89 Countries from WHO's Project Atlas. J Ment Health Policy Econ 2003; (6): 135-143.

Vázquez-Barquero JL, García J. Deinstitutionalization and psychiatric reform in Spain. Eur Arch Psychiatry Clin Neurosci 1999; 249: 128-135.

World Health Organisation. The World Health Report 2001. Mental health: new understanding, new hope. Geneva: World Health Organisation; 2001.

World Health Organisation. Atlas. Mental health resources around the world. Geneva: World Health Organisation; 2005.

Address for correspondence:

Luis Salvador-Carulla, MD

PSICOST Research Association

San Marcos 6 Jerez 11403 SPAIN

Telephone +34-956-311587 Fax +34-956-331759

E-mail: luis.salvador@telefonica.net 